\title{
A Imagem da Cidade em Fotografias Online: Estudo de Caso do Site Flickr sobre Curitiba (Paraná, Brasil)
}

\author{
The City Image in Online Photos: Case Study on Flickr Website \\ about Curitiba (Paraná, Brazil)
}

\author{
Franciele Cristina Manosso (MANOSSO, F. C.) ${ }^{*}$ \\ Camila Bizinelli (BIZINELLI, C.) ${ }^{* * *}$ \\ José Manoel Gonçalves Gândara (GÂNDARA, J. M. G.) ${ }^{* * * *}$
}

\begin{abstract}
RESUMO - A imagem dos destinos turísticos pode ser considerada uma forma eficaz de atração, principalmente quando bem trabalhada pelo marketing. Nesta conjuntura, a presente pesquisa tem como objetivo central a compreensão de como a imagem de Curitiba (Paraná, Brasil) vem sendo percebida pelos turistas que a visitam, utilizando-se como objeto de estudo a rede social Flickr, onde tanto turistas quanto moradores podem postar fotografias a respeito do que vivenciam em seu cotidiano e em suas visitas aos destinos. Para tal, utilizou-se como metodologia, a pesquisa bibliográfica e documental, bem como, as categorias de análise discutidas por Donaire e Galí (2011). Nesse sentido, como resultado da pesquisa destaca-se que os atrativos turísticos de Curitiba são considerados relevantes para o turista, sendo os parques e praças àqueles que mais se destacaram nas fotografias analisadas. Outro aspecto que deve ser salientado é a postagem de fotos que mostram Curitiba panoramicamente, isto é, que buscam destacar a dinamicidade encontrada na cidade e, não somente, alguns pontos centrais, mostrando assim, que Curitiba tem muito a oferecer tanto aos seus moradores quanto aos turistas que a visitam.
\end{abstract}

Palavras-Chave: Turismo; Marketing; Imagem; Fotografia; Flickr; Curitiba - PR.

ABSTRACT - The image of tourist destinations can be considered an effective form of attraction, especially when crafted by the marketing. At this juncture, the present research has mainly focused on understanding how the image of Curitiba (Paraná,

\footnotetext{
* Formação: Graduação em Turismo (Bacharelado) e Mestranda em Geografia pela Universidade Federal do Paraná (UFPR). Bolsista da Coordenação de Aperfeiçoamento de Pessoal de Nível Superior (CAPES). Endereço físico para correspondência: Rua Santa Rita, 542 (Cidade Jardim). CEP: 83035-250 - São José dos Pinhais (Paraná) - Brasil. Telefone para contato: (41) 9937-0655. E-mail: franmanosso@hotmail.com

** Formação: Graduação em Turismo (Bacharelado) e Mestranda em Geografia pela Universidade Federal do Paraná (UFPR). Bolsista da Coordenação de Aperfeiçoamento de Pessoal de Nível Superior (CAPES). Endereço físico para correspondência: Rua Maria Bizinelli, 480 (Campo Comprido). CEP: 81210-154 Curitiba (Paraná) - Brasil. Telefone para contato: (41) 9624-8874. E-mail: ca bizinelli@ hotmail.com

*** Formação: Graduação em Turismo (Bacharelado) pela UFPR, Mestrado em Gestão do Turismo pela Scuola Superiore del Commercio del Turismo i dei Servizzi de Milão, Doutorado em Turismo e Desenvolvimento Sustentável pela Universidad de Las Palmas de Gran Canária. Atividade profissional: Professor e Pesquisador do Departamento de Turismo, do curso de Graduação em Turismo, do Mestrado e Doutorado em Geografia e do Mestrado em Turismo da Universidade Federal do Paraná (UFPR). Endereço físico para correspondência: Rua Doutor Faivre, 405 - $3^{\circ}$ andar (Centro). CEP: 80060140 - Curitiba (Paraná) - Brasil. Telefone para contato: (41) 3360-5109. E-mail: jmggandara@yahoo.com.br
} 
Brazil) has been perceived by the tourists who visit it, using as research object the Flickr social network, where both tourists and residents can post photographs about they experience in their daily lives and in the visits on destinations. For this, it was used as a methodology, the literature and documental research, as well as categories of analysis discussed by Donaire and Galí (2011). So, as result of the research it was found that the tourist attractions in Curitiba are considered relevant for the tourist, being parks and squares those which were more cited in the photographs analyzed. Another interesting aspect which should be noted is posting photos that show Curitiba panoramically, which ones seek to highlight the dynamics found in the city, and not only some central places showing thus that Curitiba has much more to offer both for to their residents and for the tourists who visit it.

Key words: Tourism; Marketing; Image; Photography; Flickr; Curitiba-PR. 


\section{INTRODUÇÃO}

A imagem dos destinos turísticos pode ser utilizada como um instrumento de cunho estratégico para que se atraia um maior número de visitantes, sendo a imagem projetada considerada como um conjunto de ações comunicativas trabalhadas pelo destino turístico e a imagem percebida pelos turistas, bem como, o reflexo do que foi projetado pelos meios de comunicação e da qualidade da experiência vivenciada pelos visitantes. Neste sentido, percebe-se que, muitas vezes, a imagem apresentada de maneira estereotipada pode não corresponder com o que o turista percebe durante a sua vivência no destino turístico (GÂNDARA, 2008).

Por essa razão, o estudo da imagem dos destinos turísticos torna-se relevante, para que se possa analisar como estes estão sendo apresentados aos turistas, tanto potenciais quanto reais. A presente pesquisa tem como objetivo compreender como a imagem de Curitiba (Paraná, Brasil) vem sendo percebida, ou seja, o que o turista fotografa ao visitar a cidade podendo-se, assim, perceber quais motes desta são considerados destaques para àqueles que desfrutam de Curitiba, como um destino turístico. Para tal, utilizou-se como objeto de pesquisa a rede social Flickr, onde tanto turistas quanto moradores podem postar fotografias a respeito do que vivenciam em seu cotidiano, bem como, nas visitas realizadas ao destino turístico.

Realizou-se uma pesquisa bibliográfica e documental para que se obtivesse uma visão mais abrangente da temática, bem como, a análise do que os turistas vêm 'postando' nas mídias sociais focando-se, como citado anteriormente, no Flickr, considerando-se para esse artigo as dez primeiras páginas encontradas ao pesquisar a cidade de Curitiba na rede social em questão totalizando-se, assim, 235 fotos pesquisadas. Neste contexto, o artigo abordará a importância da imagem para os destinos turísticos, o marketing e aspectos inerentes à formação da imagem, e o panorama da atividade turística em Curitiba.

\section{IMAGEM DOS DESTINOS TURÍSTICOS}

A imagem turística, segundo Urry (1990), deve ser considerada um elemento básico da experiência, pois como afirma Downling (1986) esta pode ser definida a partir 
de pontos de vista específicos que surgem através da descrição, memória ou outras formas de associação relacionadas a determinados destinos turísticos, podendo ser considerada o resultado das interações entre a impressão dos turistas, as crenças existentes, os pensamentos e, por fim, os sentimentos referentes a um determinado local.

Antelo (2004) discorre que toda a imagem pode ser considerada uma representação, de caráter global, podendo idealizar um território, uma identidade, ou seja, a imagem pode constituir, operar e inserir parâmetros coletivamente aceitos. Crompton (1979) salienta, ainda, que a imagem de um destino turístico pode ser ponderada a partir do somatório de todas as impressões, experiências, emoções e recordações que o turista estabelece com a localidade que visitou. Portanto, a imagem pode ser considerada a projeção mental que o individuo forma em relação ao que ele vivenciou.

Valls (1992) destaca que um destino turístico divulga as imagens projetadas pelas ações comunicativas e pela experiência que o turista tem ao visitar determinada localidade. Logo, a imagem turística constitui um fator chave para a criação de ações de divulgação dos destinos, pois é um dos principais elementos influenciadores na escolha de uma localidade pelo turista. Torres (2006, p. 6), por sua vez, salienta a questão do imaginário criado tanto pelas fotografias quanto pelo que é divulgado pelas ações comunicativas quando cita que: “ [...] as representações das cidades apresentadas pelos veículos de comunicação acabam por fixarem cenas, retratar, ilustrar, reproduzir e sintetizar a realidade de uma cidade".

Deve-se levar em consideração o que vem sendo divulgado dos destinos turísticos, tanto em veículos de comunicação pagos, quanto nas redes sociais, locais onde os próprios turistas compartilham suas experiências e percepções. Gândara (2008) e Prebensen (2007) salientam que deve existir uma coerência entre a imagem anterior à visita, ou seja, as que geram expectativas nos turistas, e a realidade encontrada ao desfrutar do destino turístico, para que se obtenha um grau elevado de satisfação por parte do visitante, possibilitando, de tal maneira, a fidelização do mesmo.

Quando a imagem de um destino é propagada pelos meios de divulgação, ela pode ser trabalhada como um diferencial no mercado competitivo dos destinos turísticos. Desse modo, as localidades turísticas que trabalham com a imagem, desde o 
ponto de vista de diferenciação, devem levar em conta o que está sendo divulgado, e o que realmente é encontrado no destino final (GÂNDARA, 2008; HANKINSON, 2004; BIGNAMI, 2002).

A imagem previamente difundida afeta de maneira direta o comportamento de escolha, bem como, a avaliação dos destinos e as experiências turísticas vivenciadas pelos turistas (ECHTNER; RITCHIE 1991). Pode-se dizer que a imagem de um destino torna-se um instrumento relevante para o processo de tomada de decisão (MORENO GIL, BEERLI PALACIO, MARTÍN SANTANA, 2004; CHEN, TSAI 2007; BIGNÉ, SANCHÉZ, SANCHÉZ, 2001).

Chon (1990) que estuda a importância da imagem turística para os destinos, destaca o que deve ser levado em consideração quando se aborda a imagem de uma localidade frente ao turista. Os pontos citados por este autor são os seguintes:

- Influência da imagem na satisfação do turista;

- O papel da imagem no comportamento de compra, principalmente ao que se refere à tomada de decisão;

- Mudanças ocorridas na imagem da destinação;

- Influência do intercâmbio entre nações e culturas na formação e na modificação da imagem;

- A contribuição e a mensuração da imagem do destino;

- O papel da imagem e o desenvolvimento turístico.

Com o que Chon (1990) aborda sobre os pontos necessários para o estudo da imagem turística, pode-se afirmar que a mesma deve ser compreendida como um resultado dos julgamentos e valores que os indivíduos atribuem aos seus elementos, podendo ainda ser considerada um fenômeno perceptivo formado pelas interpretações racionais e emocionais dos consumidores (BALOGLU, BRINBERG, 1997; SOLHA, 1999; BALOGLU, MANGALOGLU, 2001).

Por essa razão, analisar todos os motes passíveis de contribuição para a imagem turística é fundamental, para que se possam alcançar resultados compatíveis com o desenvolvimento econômico e turístico local (ALÉN GONZÁLEZ, MUÑIZ, BARREIROS, 2012). A compreensão da definição de imagem, bem como, de elementos que a constituem, torna-se um preceito indispensável para o adequado desenvolvimento de um destino turístico (FRAIZ BREA; CARDOSO 2011). 
Tasci e Gaertner (2007) salientam que a imagem turística dos destinos pode ser considerada uma avaliação global, contendo componentes cognitivos e afetivos, sendo postulada para ser influente sobre as variáveis do comportamento do consumidor. Corroborando essa colocação Gallarza, Saura e García (2002) ressaltam que a imagem representa um conjunto de impressões e sentimentos sobre determinado destino turístico, sendo estas impressões oriundas dos atributos (atrativos, infraestrutura) deste.

Por esses motivos, o estudo da imagem dos destinos turísticos, sobretudo urbanos, objeto de estudo desta pesquisa, torna-se relevante. Pois, como afirma Castrogiovanni (2000) a cidade, discutida dentro do contexto do espaço urbano, é um mundo de representações, sendo ela de pequeno porte ou uma metrópole, que pulsa, vive, seduz, agride, transforma-se, e consequentemente modifica aqueles que nela interagem.

\section{MARKETING E TURISMO: O IMPACTO DA ERA DIGITAL NA IMAGEN DOS DESTINOS TURÍSTICOS}

O marketing, com suas ações comunicativas, é considerado fundamental na conciliação, promoção e comunicação da imagem dos destinos. Nesse sentido é imprescindível que ao divulgar uma determinada localidade não se gerem falsas expectativas, pois, são os clientes satisfeitos que podem ser fidelizados, tornando-se fundamental o conhecimento da percepção destes em relação à qualidade dos produtos e serviços que estão sendo oferecidos, principalmente, ao que se refere aos atrativos presentes em um destino turístico (GÂNDARA, 2001).

Ross (1993) salienta que o nível de expectativas dos visitantes é relevante para a formatação das estratégias do marketing de destinos, porque os esforços que prometem experiências que uma localidade não proporciona provocam uma reação negativa que reflete nas avaliações dos turistas. Esse fato deve ser levado em consideração sob a ótica do marketing, pois o mesmo pode ser considerado uma peça-chave dentro das atividades econômicas (sobretudo a turística), sendo analisado como um fator que permite garantir sucesso e bons resultados para os empreendimentos e destinos turísticos (MADEIRA, 2010). 
Kotler, Bowen e Makens (1996) definem o marketing como sendo uma ferramenta a ser utilizada para a orientação dos desejos e das necessidades dos consumidores, através de uma sinergia existente no destino turístico, para que a experiência do turista seja satisfatória ao visitar determinada localidade.

Desde esta perspectiva, surge a internet, considerada uma mídia detentora de grandes fluxos de informações que, sendo utilizada pela atividade turística, devido seu caráter intangível, passa a ser considerada um canal de comunicação eficiente para a atração de turistas para os destinos turísticos, podendo ser empregada como um primeiro recurso para o início de uma comunicação entre os potenciais turistas e os destinos turísticos (BUHALIS, 1998).

Bonn, Furr e Susskind (1998) salientam que a internet por ser considerada uma fonte de informação e que deve ser empregada dentro do marketing turístico, principalmente ao que se refere à imagem dos destinos. Isto se deve, sobretudo, às suas características peculiares, tais como: acessibilidade, conveniência da postagem, informações em tempo real, interatividade da comunicação, entre outros. Assim, podese dizer que é uma das mais importantes fontes de informação para os turistas, principalmente, ao que se refere às informações sobre as localidades que se pretende visitar. Esse fato é corroborado por alguns autores, sendo eles: Buhalis (1998), Buhalis e Licata (2002); Pan e Fesenmaier (2006); Wu, Wei e Chen (2008).

Com o advento da internet nos últimos anos, Frías et al (2012) e Vich-IMartorell (2004) salientam que a chave para o sucesso da web é a rápida identificação das necessidades do consumidor, ou seja, o contato direto com este. Esse relacionamento pode ser instituído através das mídias sociais, consideradas comunidades on-line onde pessoas compartilham seus interesses comuns e atividades, pois conteúdos são gerados pelo consumidor/turista, que quando realiza uma viagem se utiliza de uma dessas mídias para propagar sua opinião (Tripadvisor, Facebook, blogues, entre outros). Bem como, pode haver o compartilhamento de suas memórias e experiências através da postagem das fotos relacionadas àquele momento (Flickr, Instagram, Facebook, blogues, entre outros) (MIGUÉNS; BAGGIO; COSTA, 2008).

Neste sentido, Huertas (2008) defende que as opiniões e as experiências de outros consumidores podem ser consideradas uma fonte valiosa ao que se refere às informações para os turistas considerados potenciais. Isto porque, ajudam a reduzir o 
desconhecimento sobre determinado destino turístico e, consequentemente, as vivências e relatos, tanto quanto as fotografias das experiências vivenciadas anteriormente. Os quais podem ser empregados como uma forma de motivação e convencimento, podendo ser considerados mais relevantes que um folheto turístico.

O próximo tópico abordará o contexto da fotografia na atividade turística, assim como, na formação da imagem dos destinos turísticos.

\section{FOTOGRAFIA E TURISMO}

A partir do que foi discutido nos tópicos anteriores, cabe salientar que pesquisas e investigações relacionadas ao estudo da imagem tornam-se relevantes, sobretudo, ao que se refere à análise das fotografias oriundas de um passeio a um determinado destino turístico, pois estas podem ser consideradas a materialização da experiência do visitante, sendo representada através das imagens propagadas por estes (DONAIRE; GALÍ, 2011). Neste sentido, Urry (1990) destaca que a fotografia colabora para a construção social da imagem de um destino turístico, bem como, condiciona a escolha da localidade e do comportamento do turista ao visitar estes espaços.

Já Neiva Jr. (2006), salienta que a imagem é basicamente uma síntese que oferece, de modo simultâneo, traços, cores e outros elementos visuais. Contudo, Sontag (2004) transpõe esse pensamento ao abordar um tipo específico de imagem: a fotografia. Para a referida autora, as fotos são indícios, não apenas do que existe, mas, também daquilo que o indivíduo observa. O que, por sua vez, acaba tornando-se uma avaliação do mundo. Neste âmbito, Kossoy (2001) cita que o fotógrafo pode ser considerado um filtro cultural, que ao fazer a fotografia, possibilita a contemplação do que merece estima, deflagrando diversas emoções, tanto no fotógrafo, quanto na pessoa que contemplará as fotografias.

Por essa razão, Sturken e Carwright (2001) discutem que os significados das imagens não estão relacionados somente aos seus elementos, mas também, são adquiridos quando os elementos são consumidos, vistos e interpretados. Logo, os significados das fotografias podem ser criados e/ou modificados a cada vez que elas forem vistas, sendo que o contexto sócio-histórico do fotógrafo e de quem as observar influenciará de maneira direta em sua interpretação. 
Marques (2012), por sua vez, ressalta que quando se pondera acerca dos significados de uma imagem fotográfica, ou seja, quando o observador se pergunta 'quando e onde uma determinada imagem foi tirada?', 'o que ela retrata?', 'qual tipo de evento ou atrativo?' e, 'qual relação os objetos e as pessoas estabelecem entre si?', ele busca entender o que a imagem significa para si próprio e em que contexto de sua vida ela se encaixa.

Assim, quando o fotógrafo foca em determinado evento ou atrativo, deixando de realizar uma foto panorâmica do cenário, pode-se afirmar que aquilo que se encontra em destaque chamou mais atenção do que o cenário como um todo, fazendo com que a pessoa que está fotografando naquele momento, busque destacar aquele pedaço do todo e não realizar uma foto panorâmica (DONAIRE; GALLI, 2011).

Outro aspecto a ser salientado é o grau de humanização (presença da figura humana) explícito nas imagens vinculadas aos destinos turísticos, pois a desumanização, segundo Donaire e Gallí (2011) é uma constante na divulgação de determinadas localidades turísticas.

Nesse sentido, Wunder (2006) adiciona que o instante da fotografia ocorre no momento em que o encaixe entre o que está sendo fotografado e a ideia pré-existente do fotógrafo se encontram. Logo, uma fotografia é resultado de um bom e fugaz encontro, sendo este previsto ou inesperado, mas, também considerado uma busca ou intenção que possibilite ver as coisas que poderiam passar despercebidas.

Tendo ciência do que foi exposto até o presente momento, o próximo tópico abordará o panorama do turismo em Curitiba, para que se tenha uma visão abrangente da representação da atividade na cidade a ser analisada.

\section{PANORAMA DO TURISMO EM CURITIBA}

A cidade de Curitiba, capital do estado do Paraná, é um destino turístico urbano, que possui 1.751.907 habitantes (IBGE, 2010). De acordo com o Instituto Municipal de Turismo (IMT, 2011), no ano de 2010, a cidade recebeu em torno de 3.410.219 turistas que gastaram na cidade, aproximadamente, cada um a quantia de 91,15 dólares, por dia.

Segundo o estudo de demanda turística, realizado pelo Instituto Municipal de Turismo, os turistas que visitam a cidade provêm, em primeiro lugar, do próprio estado 
(36,8\%), em seguida, da região sudeste $(32,8 \%)$, sendo que as principais motivações identificadas são: 'lazer, recreação e descanso' (36,0\%), 'negócios e motivos profissionais' (26,3\%) e 'visita a parentes e amigos' (23,5\%). Nesta conjuntura, o Instituto Municipal de Turismo destaca que grande parte dos turistas define Curitiba como 'cidade com qualidade de vida' (38,5\%), seguida de 'cidade ecológica' $(16,6 \%)$ e 'cidade cultural' (12,5\%) (IMT, 2011).

Em pesquisa realizada por Horodyski, Manosso e Gândara (2012) com os visitantes de Curitiba, verificou-se que estes citam como palavras que remetem à cidade os termos: 'beleza', 'limpeza', 'elegância', 'organizada' e 'moderna'. Além desse ponto, os referidos autores indicam a importância dos parques na experiência turística.

Corroborando com tal afirmação, Ramos, Gândara e Tramontin (2008) citam que Curitiba passou por diversas alterações urbanísticas, buscando melhorar a qualidade de vida do morador, sendo que algumas dessas soluções acabaram sendo reconhecidas nacional e internacionalmente, fazendo com que a cidade fosse denominada de 'cidade com qualidade de vida' e 'cidade ecológica'.

Custódio (2006) e Pedron (2013) legitimam esse mesmo ponto de vista, ao salientarem que os principais atrativos de Curitiba são intervenções urbanísticas, ou seja, parques e praças criados para a população e que se tornaram importantes atrativos para a cidade. Segundo Souza (2013), Curitiba se destaca, também, pela existência de projetos de mobiliários urbanos únicos que, muitas vezes, são associados à imagem da cidade. Como exemplo, podem-se citar as estações tubo, utilizadas como ponto de parada de ônibus e consideradas um ícone por aqueles que visitam a cidade.

Quando se aborda a imagem de Curitiba, pode-se salientar que a mesma vem sendo construída ao longo de seu planejamento, e atualmente começa a ser trabalhada dentro da perspectiva de uma 'metrópole competitiva', é um exemplo de como a imagem de um destino turístico vem sendo trabalhada frente aos turistas que a visitam e que pretendem visita-la (FIRKOWSKI, 2007; MOURA, 2007; GÂNDARA, 2001).

Couto (2002) salienta, ainda, que nos anos 90, Curitiba colhia os 'frutos' de ser avaliada como uma das melhores cidades do mundo para se viver, sendo apresentada nesse período por algumas expressões que a caracterizavam, tais como: Capital Ecológica, Cidade Laboratório e Cidade Modelo. Sanchez (1997) e Moura (2007), desde uma perspectiva crítica, corroboram o que foi citado, ao frisarem que Curitiba é 
reconhecida pelo seu 'modelo de planejamento', principalmente ao que tange às suas intervenções urbanísticas, fortemente associadas às representações que remetem aos termos: modernidade, inovação e eficiência.

Dessa forma, pode-se alegar que a imagem de Curitiba está arrolada ao seu planejamento urbano, tornando-a, desse modo, peculiar e atrativa, sobretudo, ao que se refere ao transporte coletivo e à presença de trinta e oito áreas verdes, sendo estas consideradas os atrativos turísticos mais significativos para seus visitantes (RIBEIRO; SILVEIRA, 2006).

Neste contexto, outro aspecto de relevância e que se refere à imagem da cidade é a sua formação histórica e cultural, fortemente marcada pela presença de diversas etnias que influenciam e distinguem a sua paisagem urbana. Segundo Firkowski (2007) a década de 1990 foi de intensa transformação para a cidade de Curitiba, quando "várias atividades relacionadas aos serviços e comércio passaram a ser controladas por grupos de atuação mundial, além da implantação de duas importantes unidades da indústria automobilística e seus respectivos fornecedores" (FIRKOWSKI, 2007, p. 90). Logo, Curitiba passou a concentrar funções mais complexas, despertando, assim, o interesse de outras cidades em seu planejamento urbano (FERREIRA; FERNANDES; HUÇULAK, 2011).

Em relação ao apelo turístico da cidade, cabe aludir que a partir dos anos 90, a gestão municipal de Curitiba passou a desenvolver diversos projetos destinados ao transporte turístico que circula entre os principais atrativos da cidade (SILVA, 2012; GÂNDARA, ALBACH, VIEIRA, 2008; CUSTÓDIO, 2006). O modelo atual de transporte turístico, denomina-se Linha Turismo, e é gerido pela URBS - Urbanização de Curitiba S.A (URBS, 2013). O roteiro da Linha Turismo proporciona ao visitante um circuito para ser realizado em um dia, contemplando 24 atrativos, bem como, oferecendo informações aos passageiros, de outros passeios que podem ser realizados nos demais dias de permanência na cidade (URBS, 2013).

A abrangência e a diversidade de atrativos que compõem o roteiro da Linha Turismo favorecem o atendimento satisfatório de diversos segmentos de turistas, assim como, a implantação de um sistema de transporte turístico, integrado a diversos atrativos, estimula a visitação e, consequentemente, aumenta a circulação de turistas nestes espaços (HORODYSKI et al, 2013). 
Nesta perspectiva, cabe destacar os atrativos visitados na cidade, para que se possa ter uma visão mais abrangente de como a atividade turística vem sendo trabalhada em Curitiba e, também, o que o turista vem buscando e visitando na cidade durante a sua estadia. Desse modo, o Quadro 1 contempla os dados obtidos através de pesquisas de demanda realizadas pelo Instituto Municipal de Turismo de Curitiba, sendo esta expedida em 2011 e publicada no site Viaje Curitiba em 2012, a respeito da visitação a cada um dos atrativos da cidade.

\begin{tabular}{|l|c|}
\hline \multicolumn{1}{|c|}{ ATRATIVO } & PORCENTAGEM DE VISITANTES \\
\hline Jardim Botânico & $20,93 \%$ \\
\hline Ópera de Arame & $15,48 \%$ \\
\hline Praça Tiradentes & $11,53 \%$ \\
\hline Parque Tanguá & $7,11 \%$ \\
\hline Museu Oscar Niemeyer & $6,17 \%$ \\
\hline Torre Panorâmica & $5,78 \%$ \\
\hline Santa Felicidade & $5,20 \%$ \\
\hline Museu Ferroviário & $4,74 \%$ \\
\hline Parque Barigui & $2,81 \%$ \\
\hline Rua das Flores & $2,50 \%$ \\
\hline Bosque Alemão & $2,44 \%$ \\
\hline Rua 24 Horas & $2,17 \%$ \\
\hline Unilivre & $2,06 \%$ \\
\hline Teatro Guaíra/UFPR & $1,54 \%$ \\
\hline Bosque do Papa/Memorial Polonês & $1,52 \%$ \\
\hline Passeio Público/Memorial Árabe & $1,36 \%$ \\
\hline Setor Histórico & $1,30 \%$ \\
\hline Memorial Ucraniano & $1,08 \%$ \\
\hline Parque Tingui & $0,64 \%$ \\
\hline Paço da Liberdade & $0,40 \%$ \\
\hline Parque São Lourenço & $0,26 \%$ \\
\hline Teatro Paiol & $0,15 \%$ \\
\hline Centro Cívico & $0,07 \%$ \\
\hline Portal Italiano & $0 \%$ \\
\hline
\end{tabular}

QUADRO 1 - PORCENTAGEM DE VISITANTES NOS ATRATIVOS DE CURITIBA.

Fonte: IMT (2011); Viaje Curitiba (2012). Adaptado pelos autores, 2013.

Com a observação do quadro acima, percebe-se quais são os principais atrativos da cidade de Curitiba, destacando-se o Jardim Botânico, a Ópera de Arame e a Praça Tiradentes, como os pontos mais visitados.

Nesta conjuntura, o tópico a seguir contemplará a metodologia de pesquisa empregada neste estudo para se analisar a imagem da cidade frente aos turistas que a visitam, utilizando-se a rede social Flickr. 


\section{METODOLOGIA}

Ao que se refere à metodologia de pesquisa empregada no presente artigo, podese afirmar que a mesma consiste em uma pesquisa bibliográfica e documental, de cunho exploratório.

Diante do exposto, cabe definir o que é o Flickr, para que, desse modo, possa-se ter uma visão mais compreensiva do por que da utilização dessa rede social e do impacto da mesma para a imagem dos destinos turísticos. Segundo Cruz (2010) uma das potencialidades relevantes no Flickr é a possibilidade dos usuários criarem álbuns para o armazenamento das suas fotografias, podendo estas, serem vistas em diferentes lugares do mundo. Logo, cabe salientar que a rede social Flickr surge no ano de 2004, sendo desenvolvida por Caterina Fake e Stewart Butterfield para a empresa Ludicorp, contudo no ano seguinte foi vendida para o Yahoo (MISLOVE et al, 2008).

Neste contexto, devem ser ressaltados alguns estudos que abordam o Flickr, como objeto de pesquisa, sendo os quais: Donaire e Galí (2011); Gomes (2011); Dijck (2010); Rodrigues (2010); Cruz (2010); Fan et al (2009); Plangprasopchok, Lerman (2009); Peinado et al (2008); Aquino (2008); Nov, Naaman, Ye (2008); Mislove et al (2008); Kennedy et al (2007).

Assim, a utilização de uma rede social para a pesquisa é relevante, pois a mesma vem angariando um papel proeminente não somente como fonte para informar e promover os destinos, mas, também, como instrumento para se obter informações dos visitantes sobre determinado local.

Para uma melhor análise do que vem sendo apresentado no Flickr, tanto pelos turistas, quanto pelos moradores, foram analisadas as dez primeiras páginas da publicação, totalizando 235 fotos. A eleição desse número de páginas baseou-se no que afirmam Iversini, Cantoni e Buhalis (2009) quando salientam que devem ser considerados os resultados incidentes nas três primeiras páginas de cada busca; uma vez que, este é um número relevante para o usuário final. Assim, delimitaram-se as dez primeiras páginas, como forma de ir um pouco além do sugerido pelos referidos autores (já que, o universo de fotografias contidas no site ultrapassava a marca de meio milhão de imagens), pois assim, poderia se obter uma visão mais abarcante da maneira como Curitiba vem sendo retratada nas mídias sociais, principalmente no Flickr. 
Em relação à análise das imagens fotográficas, sobretudo, do site Flickr, adaptou-se o estudo publicado por Donaire e Galí (2011), os quais analisaram as imagens de Barcelona postadas na comunidade no ano de 2010. No estudo dos referidos autores os aspectos avaliados foram os seguintes:

- Identificação (elemento representado na fotografia - atrativos turísticos/paisagem/aspectos do espaço urbano);

- Categoria (12 categorias possíveis: monumento religioso, civil, comemorativo, equipamento recreativo, parque, elemento urbano, porto, skyline, gastronomia, praia e outros);

- Período (em que época do ano a foto foi tirada);

- Zoom (trata de analisar se a imagem se refere a um detalhe do elemento paisagístico fotografado, o elemento paisagístico todo, ou é uma foto panorâmica da paisagem);

- Grau de Humanização (se aparecem turistas, residentes, turistas e residentes ou ninguém na fotografia).

Por fim, conforme o que Laville e Dionne (1999) sugerem em seus estudos, empregou-se o emparelhamento, isto é, os resultados obtidos através da análise das fotografias do site Flickr foram comparados com o que se discutiu no marco teórico da referida pesquisa.

\section{APRESENTAÇÃO E ANÁLISE DOS RESULTADOS}

Com tudo que foi abordado até o presente momento, cabe agora apresentar os resultados da pesquisa, bem como, analisá-los e validá-los para que se obtenha uma visão mais ampla de como o turista, e até mesmo o morador observa e vivencia a cidade de Curitiba.

\subsection{IDENTIFICAÇÃO}

O primeiro aspecto a ser analisado se relaciona com a 'Identificação', que diz respeito ao elemento o qual a fotografia representa. 


\begin{tabular}{|l|c|}
\hline \multicolumn{2}{|c|}{ IDENTIFICAÇÃO } \\
\hline Atrativo turístico & 91 \\
\hline Aspectos do espaço urbano & 80 \\
\hline Paisagem & 64 \\
\hline
\end{tabular}

QUADRO 1 - ELEMENTOS DA CIDADE DESTACADOS PELOS USUÁRIOS DO FLICKR. Fonte: Os autores (2013).

Com a predominância dos atrativos turísticos nas fotografias, pode-se dizer que Curitiba destaca-se pela grande diversidade destes, o que pode ser observado pelos turistas através da Linha Turismo, que favorece o atendimento satisfatório de distintos segmentos de turistas, bem como, os moradores locais quando buscam lazer dentro da cidade. Nesse sentido, pode-se afirmar que a existência de um sistema de transporte turístico que integra um número considerável de atrativos, estimula a visitação, consequentemente aumenta a circulação de turistas nestes espaços (HORODYSKI, MANOSSO, GÂNDARA, 2012; RAMOS, GÂNDARA, TRAMONTIN, 2008).

Nesta conjuntura, Gândara (2008) salienta que a imagem do destino turístico pode se tornar um fator competitivo, assim, o foco nos atrativos turísticos faz com que o turista compreenda de maneira mais abrangente o que vai encontrar na cidade. Nesse sentido Mathieson e Wall (1982) destacam que o que vem sendo divulgado pelas cidades é relevante, principalmente, devido ao fato que a imagem transmitida tanto pelos turistas quanto pelo destino é essencial para a tomada de decisão no momento da escolha de uma localidade a se visitar.

Huertas (2008) salienta que as fotografias representam as experiências vividas pelos turistas em determinado destino, pois os mesmos tendem a 'materializar' sua experiência através das fotos, bem como, dos comentários postados nas redes sociais, propagando-se, assim, sua opinião do que foi vivenciado ao se visitar o destino turístico. Urry (1990) ressalta esse aspecto quando considera a imagem turística como um elemento básico da experiência, pois a mesma pode ser definida a partir da memória proveniente do turista.

\subsection{ELEMENTOS DE INTERESSE}

O Quadro 2 contempla os elementos de interesse encontrados na rede social Flickr quando se pesquisa Curitiba. 


\begin{tabular}{|l|c|l|c|}
\hline \multicolumn{4}{|c|}{ ELEMENTOS DE INTERESSE } \\
\hline \multicolumn{1}{|c|}{ ELEMENTO DE INTERESSE } & FREQUÊNCIA & ELEMENTO DE INTERESSE & FREQUÊNCIA \\
\hline Curitiba (vista panorâmica) & 42 & Praça do Japão & 2 \\
\hline Jardim Botânico & 37 & Calçadas & 2 \\
\hline Centro Histórico & 27 & Souvenirs & 2 \\
\hline $\begin{array}{l}\text { Infraestrutura/Sinalização/ } \\
\text { Mobiliário Urbano }\end{array}$ & 24 & Bosque Polonês & 2 \\
\hline Edifícios/Arquitetura & 20 & Praça da Espanha & 2 \\
\hline Ônibus/Tubo Ligeirinho & 13 & Torre Panorâmica - Oi & 2 \\
\hline Museu Oscar Niemeyer & 12 & Aeroporto & 1 \\
\hline Vegetação Endêmica & 10 & Teatro Paiol & 1 \\
\hline Rua XV de Novembro & 9 & Rua 24 Horas & 1 \\
\hline Parque Tanguá & 5 & Bosque Alemão & 1 \\
\hline Igrejas & 5 & Mercado Municipal & 1 \\
\hline Oppera de Arame & 4 & Passeio Público & 1 \\
\hline Parque Barigui & 4 & Fatores Climáticos (geada) & 1 \\
\hline Parque Tingui & 3 & Parque Passaúna & 1 \\
\hline
\end{tabular}

QUADRO 2 - ATRATIVOS CONSIDERADOS ELEMENTOS DE INTERESSE PELOS USUÁRIOS DO FLICKR.

Fonte: Os autores, 2013.

Com o Quadro 2 percebe-se que o aspecto mais fotografado pelo turista é a cidade de Curitiba como um todo, ou seja, o usuário busca postar fotografias que mostrem Curitiba de maneira panorâmica, isto é, que revelem ao turista ou morador a paisagem de Curitiba e sua dinamicidade, pois como afirma Castrogiovanni (2000) a cidade, discutida dentro do contexto do espaço urbano, é um mundo de representações, sendo ela de pequeno porte ou uma metrópole. Logo, o destaque cedido a Curitiba como um todo é relevante, pois como cita Valls (1992) as imagens turísticas divulgadas são aquelas projetadas pela experiência do turista e do morador dentro do destino turístico.

Ao que diz respeito à imagem de Curitiba, pode-se alegar que esta se encontra arrolada ao seu planejamento urbano, tornando-a, desse modo, peculiar e atrativa em alguns aspectos, sobretudo, ao que se refere ao transporte coletivo e à presença de trinta e oito áreas verdes, sendo estas consideradas os atrativos turísticos mais significativos para seus visitantes (RIBEIRO; SILVEIRA, 2006).

Ainda, a respeito de pontos considerados de interesse pelos turistas, tem-se o mobiliário urbano da cidade, representado pelas estações-tubo, o planejamento focado na melhoria a qualidade de vida da população e que passaram a ser associadas à imagem da cidade (SOUZA, 2013; RAMOS, GÂNDARA, TRAMONTIN, 2008). Sendo, então, associada a alguns termos pelo turista, sendo os quais: 'beleza', 'limpeza', 'elegância', 'organizada' e 'moderna'. 
O Instituto Municipal de Turismo (IMT, 2011) corrobora alguns pontos encontrados pela pesquisa, principalmente, quando aborda os atrativos mais visitados da cidade, sendo o qual o Jardim Botânico, que possui um número expressivo de fotos postadas na rede social Flickr, demonstrando que este atrativo turístico pode ser considerado um ícone da cidade. Também mereceram destaque em ambas pesquisas os edifícios do Centro Histórico e o Museu Oscar Niemeyer.

\subsection{CATEGORIA}

O Quadro 3 destaca as categorias dos atrativos representados nas fotografias divulgadas.

QUADRO 3 - CATEGORIAS DE ATRATIVOS - FLICKR

\begin{tabular}{|l|c|}
\hline \multicolumn{2}{|c|}{ CATEGORIAS } \\
\hline Parque e Praça & 59 \\
\hline Outros & 55 \\
\hline Elemento Urbano & 53 \\
\hline Skyline & 42 \\
\hline Equipamento Recreativo & 8 \\
\hline Monumento Religioso & 8 \\
\hline Civil & 5 \\
\hline Comemorativo & 3 \\
\hline Gastronomia & 2 \\
\hline
\end{tabular}

Fonte: Os autores, 2013.

Com a análise das fotografias publicadas percebeu-se a estima existente ao que diz respeito aos Parques e Praças presentes na cidade de Curitiba. Nesse sentido, a importância destes ocorre devido ao que citam Couto (2002) e Pedron (2013) quando abordam que nos anos 90, Curitiba colhia os 'frutos' de ser avaliada como uma das melhores cidades do mundo para se viver. Logo, o cunho de Capital Ecológica faz com que os turistas que visitam a cidade busquem conhecer atrativos que remetem a essa temática, focando-se, então, nos parques e praças localizados na cidade. Em pesquisa, Horodyski, Manosso e Gândara (2012) salientam a importância destes atrativos nas experiências turísticas vivenciadas em Curitiba, corroborando o resultado da pesquisa quando se analisa um grande número de fotos que contemplam os parques e praças da cidade. 


\section{4. $\mathrm{ZOOM}$}

O Quadro 4 apresenta a questão do zoom da fotografia, analisando-se principalmente se o fotógrafo capta apenas o atrativo ou todo o contexto presente no momento da captura da imagem.

\begin{tabular}{|l|c|}
\hline \multicolumn{2}{|c|}{ ZOOM } \\
\hline Todo & 101 \\
\hline Detalhe & 76 \\
\hline Panorâmica & 58 \\
\hline
\end{tabular}

QUADRO 4 - ZOOM - DETALHES DA CAPTAÇÃO DAS FOTOGRAFIAS.

Fonte: Os autores, 2013.

Ao que se refere ao Zoom das fotografias, percebeu-se que as mesmas buscavam capturar o todo da paisagem de Curitiba, pois como cita Neiva Jr. (2006) a imagem é basicamente uma síntese, que oferece, de modos simultâneos traços, cores e outros elementos visuais. Sontag (2004) suplanta esse raciocínio quando salienta que a fotografia, um tipo específico de imagem, pode ser considerada representação de indícios não apenas do que existe, mas também daquilo que o indivíduo observa, tornando-se, desse modo, uma avaliação do mundo. Por sua vez, Torres (2006) destaca a questão do imaginário criado pela propagação das fotografias, que cada vez mais representam a dinamicidade e o cotidiano das cidades, sendo elas turísticas ou não.

Em seguida, buscam-se os detalhes, pois como citam Donaire e Galí (2011) alguns atrativos chamam mais atenção que outros, fazendo com que se busque analisar os detalhes do que o entorno onde o atrativo se encontra, gerando assim um número considerável de imagens que busquem detalhar o atrativo especificadamente.

\subsection{HUMANIZAÇÃO}

O Quadro 5 apresenta o grau de humanização das fotografias, ou seja, quais fotos apresentam elemento humano.

\begin{tabular}{|l|l|}
\hline \multicolumn{2}{|c|}{ GRAU DE HUMANIZAÇÃO } \\
\hline Sem Presença da Figura Humana & 140 \\
\hline Presença da Figura Humana & 95 \\
\hline
\end{tabular}

QUADRO 5 - GRAU DA HUMANIZAÇÃO DAS FOTOGRAFIAS DO FLICKR Fonte: Os autores, 2013. 
Ao destacar-se o Grau de Humanização das fotografias divulgadas na comunidade Flickr, com a análise do quadro 5, percebe-se que a maioria encontrava-se desumanizada, ou seja, não possui nenhum indivíduo. Essa tendência é corroborada por Donaire e Galí (2011), quando os mesmos citam a preponderância da desumanização na maioria das imagens veiculadas nas promoções dos destinos turísticos.

Nesse sentido, de desumanização das fotografias, cabe destacar a importância destas para construção da imagem dos destinos turísticos podendo, também, ser consideradas condicionantes na escolha da localidade, bem como, do comportamento do turista ao visitar esses espaços (URRY, 1990). Desse modo, deve ser levada em consideração a veiculação de imagens que mostrem os turistas usufruindo dos atrativos turísticos da cidade, para que desta forma, os turistas em potencial possam analisar as experiências prévias dos demais visitantes podendo obter uma visão mais abrangente do que e de quem irá encontrar no destino que irá visitar (HUERTAS, 2008).

Com a análise desses aspectos, foram percebidos os principais pontos observados pelo turista ao visitar a cidade de Curitiba.

\section{CONSIDERAÇÕES FINAIS}

A imagem dos destinos turísticos deve ser utilizada como um instrumento de cunho estratégico para que se atraia um maior número de visitantes, sendo a imagem projetada considerada como um conjunto de ações comunicativas trabalhadas por um destino turístico e a imagem percebida pelos turistas aquela reflexo da imagem projetada e da qualidade da experiência vivenciada pelos turistas. Logo, o presente trabalho teve como objetivo central compreender como a imagem de Curitiba (Paraná, Brasil) estava sendo percebida pelos turistas, a partir das fotografias postadas na rede social Flickr.

Neste sentido, a utilização do Flickr, que tem como objetivo o compartilhamento de fotos oriundas das experiências vivenciadas pelos seus usuários é importante, devido à relevância que a internet vem ganhando nos últimos anos, tornando-se um canal de comunicação mais rápido entre turista e destino. Outro ponto a ser salientado ao que diz respeito à utilização do Flickr para a análise da imagem de Curitiba é a necessidade de 
se compreender o que o turista, bem como, o morador percebe da cidade, para que desse modo, possa-se comparar, em estudos futuros, com o que a cidade vem divulgando em sua divulgação oficial.

Com a realização da referida pesquisa pôde-se perceber que o principal aspecto observado pelos turistas se referiu aos atrativos turísticos de Curitiba, principalmente, os parques e as praças presentes na cidade, pontos turísticos trabalhados de maneira ampla na Linha Turismo. Também mereceram destaque os edifícios do Centro Histórico e o Museu Oscar Niemeyer. Os elementos de interesse representados nas fotografias, que em sua maioria, foram fotos panorâmicas de Curitiba, mostrando a dinamicidade da cidade, bem como, o planejamento urbano pela qual a cidade ficou conhecida, ou seja, se percebeu o impacto da imagem projetada na imagem percebida. Em relação ao zoom constatou-se que a maioria das fotografias buscava representar o todo da cidade. E por fim, sobre a humanização percebeu-se que as fotografias não continham pessoas, ou seja, eram desumanizadas como a maioria das fotos veiculadas pelos destinos.

Neste contexto, e a partir do que foi analisado nas fotografias postadas na rede social Flickr, alguns outros aspectos devem ser levados em consideração, em pesquisas futuras, sendo os quais: analisar de acordo com os conceitos da economia da experiencia de Pine e Gilmore (1999) as dimensões da experiência na qual a fotografia se enquadra, para que se possa obter uma visão mais abrangente da experiência do turista na cidade, bem como, realizar uma comparação entre o que foi encontrado nas redes sociais e aquilo que está sendo divulgados pelos destinos turísticos.

\section{REFERÊNCIAS}

ALÉN GONZALÉZ, M. E.; MUÑIZ, D. R. T.; BARREIROS, S. D. Motivaciones y formación de imágenes en el destino turístico Ourense. Revista Cultura e Turismo CULTUR, Bahia, ano 6, n. 1, p. 107-124, 2012.

ANTELO, R. Potências da imagem. Chapecó: Argos, 2004.

AQUINO, M. C. A folksonomia como hipertexto potencializador de memória coletiva: um estudo dos links e das tags no de.licio.us e no Flickr. Liinc Revista, v. 4, n. 2, p. 303-320, 2008.

BALOGLU, S.; BRINBERG, D. Affective images of tourism destinations. EUA: TTRA. Journal of Travel Research, v. 35, n. 4, p. 11-15, 1997. 
BALOGLU, S.; MANGALOGLU, M. Tourism destination images of Turkey, Egypt, Greece, and Italy as perceived by US-based tour operators and travel agents. Tourism Management, v. 22, n. 1, p. 1-9, 2001.

BIGNAMI, R. V.S. A imagem do Brasil no turismo: construção, desafios e vantagem competitiva. São Paulo: Aleph, 2002.

BIGNÉ, J. E., SANCHEZ, M. I., SÁNCHEZ, J. Tourism image, evaluation variables and after purchase behavior: inter-relationship. Tourism Management, v. 22, n. 6, p. 607-616, 2001.

BONN M. A.; FURR H. L.; SUSSKIND A. M. Using the Internet as a pleasure travel planning tool. An examination of the sociodemographic and behavioural characteristics amongst internet users and nonusers. Journal of Hospitality and Tourism Research, v. 22, n. 3, p. 303-317, 1998.

BUHALIS D. Strategic use of information technologies in the tourism industry. Tourism Management, v. 19, n. 5, p. 409-421, 1998.

BUHALIS D, LICATA C. The future of eTourism intermediaries. Tourism Management, v. 23, n. 3, p. 207-220, 2002.

CASTROGIOVANNI, A. C. Turismo e ordenação no espaço urbano. In: . Turismo urbano. São Paulo: Contexto, 2000, p.23-32.

CHEN, C.; TSAI, D. How destination image evaluate factors affect behavioural intentions. Tourism Management, v. 28, p. 1115-1122, 2007.

CHON, K. The role of destination image in Tourism: a review and discussion. Revue de Tourisme, v. 45, n.2, p. 2-9, 1990.

COUTO, I. C. Olhares da cidade: Curitiba e suas representações. Tuiuti: Ciência e Cultura, Curitiba, n. 28, FCHLA 4, p. 225-247, 2002.

CROMPTON, J. An assessment of the image of Mexico as a vacation destination and the influence of geographical location upon that image. Journal of Travel Research, v. 17, n. 4, p. 18-23, 1979.

CRUZ, S. Blogue, YouTube, Flickr e Delicious: Software Social. In: CARVALHO, A. A. A. Manual de Ferramentas da web 2.0 para Professores. Ministério da Educação, 2010 .

CUSTÓDIO, R. B. A Influência das Intervenções Urbanísticas na Atividade Turística da Cidade de Curitiba. Dissertação de Mestrado. Programa de PósGraduação em Gestão Urbana. Curitiba, Pontíficia Universidade Católica do Paraná, 2006.

DIJCK, J. Flickr and the culture of connectivity: Sharing views, experiences, memories. Memory Studies, v. 4, n. 4, p. 401-415, 2010. 
DONAIRE, J.A.; GALÍ, N. La imagen turística de Barcelona en la comunidad de Flickr. Cuadernos de Turismo, Espanha, v. 27, p. 291-303, 2011.

DOWLING, G. R. Managing your corporate image, Industrial Marketing Management, v. 15, p. 109-15, 1986.

ECHTNER, C. M.; RITCHIE, J. R. B. The meaning and measurement of destination image. The Journal of Tourism Studies, v. 14, n. 1, p. 37-47, 1991.

FAN, J.; KEIM, D.A.; GAO, Y.; LUO, H.; LI, Z. JustClick: personalized image reccomendation via exploratory search from large-scale Flickr images. In: Jornal IEEE Transactions on Circuits and Systems for Video Technology, v. 19 n. 2, p. 273-288, 2009.

FERREIRA, A. G.; FERNANDES, F. A.; HUÇULAK, J. A internacionalização de Curitiba: Uma análise a partir de equipamentos urbanos de consumo e lazer. In: Rev. GEOMAE, Paraná, v. 2, n. 1 p. 17 - 35, 2011.

FIRKOWSKI, O. Internacionalização e produção de novos espaços urbanos em Curitiba (Brasil). In: FICYUrb - International Conference of Young Urban Researchers, 1 2007, Lisboa. Anais... Lisboa, 2007.

FRAIZ BREA, J. A.; CARDOSO, L. Tourism Destination Image: Reflexão sobre as principais Investigações Internacionais. Revista de Cultura e Turismo - CULTUR, Ilhéus, v. 5, n. 2, 2011.

FRÍAS, D. M.; RODRÍGUEZ, M. A.; CASTAÑEDA, J. A.; SABIOTE, C. M.; BUHALIS, D. The formation of a Tourist destination's image via information sources: the moderating effect of culture. International Journal of Tourism Research, v. 14, n. 5, p. 437-450, 2012.

GALlARZA, M. G; GARCIA, H. C.; SAURA, I. G. Destination image: towards a conceptual framework. Annals of Tourism Research, New York, v. 29, n. 1, p. 56-78, 2002.

GÂNDARA, J. M. G. La Imagen de Calidad Ambiental Urbana como Recurso Turístico: El Caso de Curitiba, Brasil. Tese (Doutorado em Turismo e Desenvolvimento Sustentável), Universidad de Las Palmas de Gran Canária, Espanha, 2001.

GÂNDARA, J. M. G. A Imagem dos Destinos Turísticos Urbanos. Revista eletrônica de Turismo Cultural, São Paulo, Número Especial, p. 1-22, 2008.

GÂNDARA, J. M. G; ALBACH, V. M.; VIEIRA, V. B. A Gestão Responsável de Unidades de Conservação e o Turismo: Uma Análise Comparativa entre Curitiba e Joinville. V SEMINTUR - SEMINÁRIO DE PESQUISA EM TURISMO DO MERCOSUL. Anais...Caxias do Sul, 2008. 
BONFIM, I. O. B.; BAHL, M. A cidade de Curitiba e suas imagens simbólicas. In: SEMINÁRIO DA ASSOCIAÇÃO NACIONAL DE PESQUISA E PÓSGRAdUAÇÃO EM TURISMO, 7., 2010, São Paulo. Anais... São Paulo: Aleph, 2010. p. 1-15.

GOMES, V. J. B. M. Interações em redes de compartilhamento de fotografias: Performances e construção de significados no Flickr. Dissertação de Mestrado - Mestre em Comunicação e Cultura Contemporâneas - Programa de Pós-Graduação em Comunicação e Cultura Contemporâneas, Universidade Federal da Bahia, 2011.

HANKINSON, G. The brand images of tourism destinations; a study of the saliency of organic images, Journal of Product and Brand Management, 13, 2004.

HORODYSKI, G. S.; MANOSSO, F. C; BIZINELli, C.; GÂNDARA, J. M. G. Souvenirs Gastronômicos: Alimentos e bebidas como lembranças de viagem, um estudo de caso em Curitiba - Brasil. (Inédito - Em processo de Avaliação), 2013.

HORODYSKI, G. S.; MANOSSO, F. C.; GÂNDARA, J. M. G. O consumo de souvenirs e a experiência turística em Curitiba (PR). Caderno Virtual de Turismo, v. 12, n. 3, p. 323-342, 2012.

HUERTAS, A. Aplicación de la Web 2.0 a los destinos turísticos. Implantación y diferencias. In: Congreso Turismo y Tecnologías de la Información y las Comunicaciones, 1, 2008, Málaga. Anais... Málaga, 2008, p. 1-16.

IMT. INSTITUTO MUNICIPAL DE TURISMO. Pesquisa de demanda turística: perfil e opinião - Curitiba - 2010. Curitiba, 2011.

IBGE. INSTITUTO BRASILEIRO DE GEOGRAFIA ESTATÍSTICA. Censo de Curitiba, 2010. Disponível em: http://www.censo2010.ibge.gov.br/sinopse/index.php?uf=41\&dados=0 > Acesso em 20 mar. 2014.

INVERSINI, A.; CANTONI, L.; BUHALIS, D. Destination's information competition and web reputation. Information Technology \& Tourism, v. 11, p. 221-234, 2009.

KENNEDY, L.; NAAMAN, M.; AHERN, S.; NAIR, R.; RATTENBURY, T. How Flickr helps us make sense of the world: context and content community-contributed media collections. In: INTERNATIONAL CONFERENCE IN MULTIMEDIA, 15, 2007, Alemanha. Anais... Alemanha, 2007, p. 631-640.

KOTLER, P.; BOWEN, J.; MAKENS, J. Marketing for Hospitality and Tourism. Upper Saddle River, N.J.: Prentice Hall, 1996.

KOSSOY, B. Fotografia \& história. 2. ed. São Paulo: Ateliê Editorial, 2001. 
LAVILLE, C.; DIONNE, J. A construção do saber: manual de metodologia da pesquisa em ciências humanas. Porto Alegre: Editora Artes Médicas Sul Ltda.: Belo Horizonte: Editora UFMG, 1999.

MADEIRA, N. Marketing e Comercialização de Produtos e Destinos. Porto: SPI Sociedade Portuguesa de Inovação, 2010.

MARQUES, I. Imagear: o Lugar, os Viajantes e as Imagens. In: Geograficidade, v.2, Número Especial: 54-63, 2012.

MATHIESON, A. WALL, G. Tourism: economic, physical and social impacts. Londres: Longman, 1982.

MIGUÉNS, J.; BAGGIO, R.; COSTA, C. Social Media and Tourism Destinations: TripAdvisor Case Study. In: IASK ATR2008 - Advances in Tourism Research, 1, 2008, Aveiro, Portugal. Anais... Aveiro, 2008, p. 01-06.

MISLOVE, A.; KOPPULA, H. S.; GUMMADI, K. P.; DRUSCHEL, P.; BHATTACHARJEE, B. Growth of the Flickr social network. In: Workshop on Online Social Networks, 1, 2008, Seattle. Anais... Seattle, 2008, p. 25-30.

MORENO GIL, S.; BEERLI PALACIO, A. e MARTÍN SANTANA, J. La Imagen de Gran Canaria como destino turístico. Vector plus: miscelánea científico - cultural, n. 23, p. 71-78, 2004.

MOURA, R. O turismo no projeto de internacionalização da imagem de Curitiba. Turismo. Visão e Ação, Santa Catarina, v. 9, p. 341-357, 2007.

NEIVA JR., E. A imagem. São Paulo: Ática, 2006.

NOV, O.; NAAMAN, M.; YE, C. What drives content tagging: the case of photos on Flickr. In: SIGCHI Conference on Human Factors in Computing Systems, 26, 2008, Itália. Anais... Itália, 2008, p. 1097-1100.

PAN B.; FESENMAIER D. R. Online information search. Vacation planning process. Annals of Tourism Research, New York, v. 33, n. 3, p. 809-832, 2006.

PEDRON, M. A Experiência dos Turistas nos Parques de Curitiba/PR. Dissertação de Mestrado - Mestre em Geografia, Programa de Pós-Graduação em Geografia, Universidade Federal do Paraná, 2013.

PEINADO, V.; ARTILES, J.; GONZALO, J.; BARKER, F.; LÓPEZ-OSTENERO, F. FlickLing: a multilingual search interface for Flickr. Working Notes for the CLEF Workshop, 2008.

PINE II, B. J.; GILMORE, J. H. The Experience Economy: work is theatre \& every business a stage. Massachusetts: Ed. Harvard Business School Press, 1999. 
PLANGPRASOPCHOK, A.; LERMAN, K. Constructing folksonomies from userspecified relation on Flickr. In: INTERNATIONAL CONFERENCE ON WORLD WIDE Web, 18, 2009, Madrid. Anais... Madrid, 2009, 781-790.

PREBENSEN, N. K. Exploring tourists' images of a distant destination. Tourism Management, 28, n. 3, p. 747- 756, 2007.

RAMOS, S. E. V. C.; GÂNDARA, J. M. G.; TRAMONTIN, R. Turismo e planejamento urbano: uma análise sobre o caso de Curitiba. Seminário da Associação Nacional de Pesquisa e Pós-Graduação em Turismo, 5, 2008, Belo Horizonte. Anais... Belo Horizonte, 2008.

RIBEIRO, R. M.; SILVEIRA, M. A. Planejamento Urbano, Lazer e Turismo: Os Parques Públicos em Curitiba - PR. Revista Turismo - Visão e Ação, Santa Catarina v. 8 , n. 2 p. $309-321,2006$.

RODRIGUES, A. A. A. Folksonomia: Análise de etiquetagem de imagens no Flickr. Dissertação de Mestrado - Mestre em Ciência da Informação - Programa de PósGraduação em Ciência da Informação - Universidade Federal de Minas Gerais, 2010.

ROSS, G. F. Destination Evaluation and Vacation Preferences. Annals of Tourism Research. New York, v. 20, n. 3, p. 477-489, 1993.

SÁNCHEZ, F. Cidade espetáculo: política, planejamento e city marketing. Curitiba: Palavra, 1997.

SILVA, R. R. S. Avaliação dos Equipamentos e Serviços Turísticos do Jardim Botânico, Curitiba, Paraná, (Brasil). Revista Turismo em Análise, São Paulo, v. 23, n. $1,2012$.

SOLHA, K. T. Divulgação de Imagens Turísticas: o exemplo de Porto Seguro (Bahia). Dissertação de Mestrado apresentada no curso de Pós-Graduação em Ciências, na área de Relações Públicas, Propaganda e Turismo. Escola de Comunicação e Artes da Universidade de São Paulo, 1999.

SONTAG, S. Ensaios sobre a Fotografia. Tradução de Rubens Figueiredo. São Paulo: Cia. das Letras, 2004.

SOUZA, T. A. Mobiliário Urbano como elemento de produção e transformação do Espaço Urbano Público e Turístico em Curitiba (PR - Brasil) e Montreal (QCCanadá): a Percepção dos Turistas e da Comunidade Local. Dissertação de Mestrado Mestre em Geografia, Programa de Pós-Graduação em Geografia, Universidade Federal do Paraná, 2013.

STURKEN, M.; CARTWRIGHT, L. Practices of Looking: An Introduction to Visual Culture, Oxford University Press, 2001. 
TASCI, A. D. A.; GARTNER, W. C. Destination image and its functional relationships. Journal of Travel Research, vol. 45, n. 4, pp. 413-25, 2007.

TORRES, M. O Rio dos Viajantes: representação da cidade nos guia de turismo. In: CONGRESSO BRASILEIRO DE CIÊNCIAS DA COMUNICAÇÃO, 29, 2006, Brasília. Anais... Brasília, 2006.

URBS. URBANIZAÇAO DE CURITIBA. Linha Turismo. Disponível em: <http://www.urbs.curitiba.pr.gov.br/PORTAL/linha_turismo/>. Acesso em: mar. 2013.

URRY, J. The tourist gaze. London, Sage, 1990.

VALLS, J. F. La imagen de marca de los países. Madrid: McGraw- Hill, 1992.

VIAJE CURITIBA Confira os atrativos mais visitados pelos passageiros da linha turismo, 2012. Disponível em:

<http://ww.viajecuritiba.com.br/pt/noticia/31871/noticias/confira-os-atrativos-maisvisitados-pelos-passageiros-da-linha-turismo->. Acesso em: mar. 2013.

VICH-I-MARTORELL G. The Internet and tourism principals in the Balearic Island. Tourism and Hospitality Research, v. 5, n., p. 25-44, 2004.

WU S-I; WEI, P-L; CHEN J-H. Influential factors and relational structure of Internet banner advertising in the tourism industry. Tourism Management, v. 29, n.2, p. 221236, 2008.

WUNDER, A. Fotografias como exercício de olhar. Reunião Anual da ANPEd Associação Nacional de Pós-Graduação e Pesquisa em Educação, 29, 2010, Caxambú, Anais.... Disponível em:

<http://www.anped.org.br/reunioes/29ra/trabalhos/trabalho/GT16-2359--Int.pdf > . Acesso em: 17/03/2013, p. 1-14.

Recebido em: 30-04-2013.

Aprovado em: 29-05-2013. 